\title{
Sensemaking the 'social' in social entrepreneurship
}

\begin{abstract}
In the collective imagination, the practices and outcomes of social entrepreneurship seem to hold hope for a better future. So far, these practices have been largely assumed as idealized types with the 'social' in social entrepreneurship under explored. Such assumed neutrality, we argue, is hampering the development of a more robust theoretical corpus for understanding the phenomenon and inspiring practices that are more effective. In this paper, we analyse the sensemaking of the 'social' in social entrepreneurship by exploring the ways in which social entrepreneurs make sense of social problems and develop solutions for tackling them. Our empirical analyses of the stories of 15 social entrepreneurs point to two distinct types of sensemaking and sensegiving practices, aligned with Amartya Sen's notions of social justice. Drawing on these findings, sensemaking and social justice theory, we elaborate a 2-type social sensemaking model pertaining to the appreciation and assessment of circumstances, and the differing problem/solution combinations emerging from alternative ontological views of what constitutes a social problem.
\end{abstract}

Keywords: social entrepreneurship, sensemaking, realization, institutions, social justice, poverty. 


\section{Introduction}

In recent years, social entrepreneurship has considerably grown as an area of academic and practical importance (Stephan, Patterson, Kelly and Mair, 2016). By adopting market based approaches to the solution of social problems (Austin, Stevenson, and Wei Skillern, 2006; Bacq and Janssen, 2011), social ventures are seen as a vehicle for creating social impact and, ultimately, social change in and for a particular community (Mair and Marti, 2009; Short et al., 2009). To date, research has discussed how social entrepreneurs recognise opportunities, typically by identifying how solutions to social problems are identified through business approaches (Cohen and Winn, 2007; Corner and Ho, 2010; Di Domenico, Haugh, and Tracey, 2010; Zahra, Rawhouser, Bhawe, Neubaum, and Hayton, 2008) and how they differ from their commercial counterparts (Austin et al., 2006; Clark, Newbert, and Quigley, 2018; Estrin, Mickiewicz, and Stephan, 2016).

Further research has taken a more cautious stance, questioning the idealized conceptions of social entrepreneurship practices and the social problems (opportunities) they recognise (Dey and Steyaert, 2016; Dey and Lehner, 2017; McMullen and Bergman, 2017; McMullen and Bergman 2018; Zahra, Gedajlovic, Neubaum, and Shulman, 2009). This casts light on the neutrality of the 'social' in social entrepreneurship, which we argue is a problematic assumption. This means that the ways in which social entrepreneurs approach and define a social problem they are trying to solve is not trivial and might have consequences for their beneficiaries; since the practices implemented as a result of a particular understanding and judgement of social problems may lead to failed processes and unintended consequences. The 'social' makes reference not only to a specific group of people but how this group and its circumstances are assessed, judged and (eventually) remediated by an individual in pursuit of a better state of being for those affected.

Since this requires definition of 'good and bad things in life' (Miller, 1999) and consequent 
social repair, justice is an unavoidable add on to any examination of the 'social' in social entrepreneurship. While relevant, our current view of the social entrepreneurship process has been limited by the boundaries of entrepreneurship without further consideration of the 'social'. This, we argue, is hampering the development of a more robust theoretical corpus for understanding the phenomenon beyond current notions of opportunity recognition, development (Corner and Ho, 2010) and business models (Hlady Rispal and Servantie, 2017). In this paper, we seek to tackle the aforementioned gap by asking: how do social entrepreneurs make sense of social problems and develop entrepreneurial solutions for tackling such problems? We pick up this conversation by drawing from the theoretical social justice framing of Sen (2009) to discuss varying sensemaking, sensegiving and sensebreaking approaches to social problems.

To examine our previously highlighted research question(s), we conducted a qualitative study of 15 experienced social entrepreneurs in Chile. They were purposively selected from a larger group of social entrepreneurs in line with four criteria: self-identification, active involvement, years of operation and being in the process of entering and / or starting operations in unfamiliar social or geographical locations. By observing our data through the lens of Sen (2009)'s work on social justice and ideas from the sensemaking literature (Weick, Sutcliffe, and Obstfeld, 2005), we were able to identify a range of arrangement and realization driven practices associated with social entrepreneurs. This lead to uncovering two alternative types and permutations whereby social entrepreneurs assess, judge, comprehend, embrace, and act upon a particular social problem.

Our work delineates a number of unique sensemaking, sensegiving and sensebreaking activities. Firstly, they emphasize that social problematizing can be conformist or reflective in nature. Secondly, they demonstrate, within our two types, that the solutions developed to tackle such problems are either open or closed to further change or iteration. Thirdly, they show that 
sensegiving strategies represent approaches to communication which either seek to legitimize and align or an internalized entrepreneurial ideal of consistent collaboration. Lastly, we identify how these types break down and become re-oriented through critical junctures. The development of these types is built from Sen's (2009) broad ideas of arrangement and realization approaches to justice and augmented with prior social entrepreneurship theory.

Our work contributes to the literature in a number of ways. First, by empirically examining and unpacking the 'social' in social entrepreneurship through the lens of social justice, we provide a fine-grained theoretical understanding of the social entrepreneurship process. While uncovering these different social sensemaking types, our work consequently extends current literature by providing a more thorough explanation of the process leading to social value creation, which involves understanding the pursuit of solutions to neglected problems with positive externalities (Luke and Chu, 2013; Santos, 2012). Our alternative types lead to theoretical statements pertaining to the appreciation and assessment of circumstances and the differing practices emerging from alternative ontological views of what a social problem is and how it should be treated. In doing so, we respond to a calls from Shaw and de Bruin (2013) and Mair, Battilana, and Cardenas (2012) about a need for a more fine-grained understanding of social entrepreneurship practices, covering three key areas: the social needs and constituencies targeted, the mission of the social entrepreneur, and the processes and resources used (Pless, 2012).

Second, while uncovering differing sensemaking and sensegiving sequences of practices in social entrepreneurship, we provide a cautious view of the assumed intentionality of social entrepreneurs. Sen's (2009) social justice lens allows for this exploration by providing the theoretical language and backdrop to understanding how social entrepreneurs interpret and act upon social problems in a diverse manner. In doing so, we also avoid normative classifications of what is social and what is not, as it has been recently emphasized by Santos (2012). We do 
not argue for an incorrect approach but seek to acknowledge the different pathways to sensemaking social problems that do exist and reflected upon given Sen's (2009) normative theory. This resonates with recent arguments around the relevance of social entrepreneurs being embedded in their context and co-creating solutions (Montgomery, Dacin, and Dacin, 2012).

\section{Theoretical grounding}

\section{Social entrepreneurship and social problems}

Social entrepreneurship is the "process involving the innovative use and combination of resources to pursue opportunities to catalyse social change and/or address social needs' (Mair and Marti, 2006: 37). Despite the blurred boundaries (Peredo and McLean, 2013) and lack of a unified definition (Dacin, Dacin, and Tracey, 2011), the conceptualization introduced by Mair and Marti (2006) has been instrumental in moving social entrepreneurship research forward. Therefore, social entrepreneurship is not only about particular individuals or about businesses with primarily social objectives whose surpluses are principally reinvested for that purpose in the business or 'community'. They involve a process of employing market-based business practices to solve social problems (Grimes, McMullen, Vogus, and Miller, 2013), where the ultimate outcome is innovation that benefits the disenfranchised (George, McGahan, and Prabhu, 2012). In a developing context, this entails a process that fosters social and economic wellbeing of communities that have structurally been denied access to resources, capabilities, and opportunities (George et al., 2012; Mair and Marti, 2009).

However, what is common across social entrepreneurship research is idealized conceptions of what social entrepreneurs do, which is worryingly prominent in the heroic stories we hear in media and from the range of organisations supporting this business activity. Dacin et al. (2011: 3) discuss it as 'a more ethical and socially inclusive capitalism'. Moss, Short, Payne, 
and Lumpkin (2011: 822) conclude that social entrepreneurship 'has transformed the lives of those supporting, providing, and receiving its products and services'. Shaw and de Bruin (2013) posit that social entrepreneurship can be at the 'centre stage' of global prosperity. On the surface, what social entrepreneurs do (i.e. solve social problems) seem self-evident, but at its core is a value-based judgment by an individual on behalf of another group of persons. Social entrepreneurs hold varying views about the world that they bring to bear in the consideration of a particular social problem (Santos, 2012).

However, this literature continues to have a largely idealized notion of this domain despite at least anecdotal evidence that "social promises" made by entrepreneurs are not always met. Infamous cases such as Play Pumps in Africa that required children to play '27 hours' a day to pump the needed water to satisfy the community needs (Saunders and Borland, 2013). In many cases, the pumps were too expensive, too complex for local operation and maintenance, overreliant on child labour with a high risk of injury and based on incorrect water demand estimations (Zenios, Denend and Sheen, 2012). Reflections around this idealized notion can also be found in professional networks of development workers discussing the process whereby individuals assess, judge and try to solve social problems:

Let's pretend, for a moment, that you are a 22-year-old college student in Kampala, Uganda. You're sitting in class and discreetly scrolling through Facebook on your phone. You see that there has been another mass shooting in the US, this time in a place called San Bernardino. You've never heard of it. You've never been to the US. But you've certainly heard a lot about the gun violence there. It seems like a new mass shooting happens every week. You wonder if you could go there and get stricter gun legislation passed. You'd be a hero to the American people, a problem-solver, a lifesaver. How hard could it be? Maybe there's a fellowship for high-minded people like you to go to the US after college and train as social entrepreneurs. You could start the non-profit organization that ends mass shootings, maybe even win a humanitarian award by the time you are 30. Sound hopelessly naive? Maybe even a little deluded? It is. And yet, it's not much different from how too many Americans think about social change in the global south. If you asked a 22-year-old American about gun control in this country, she would probably tell you that it's a lot more complicated than taking some workshops on social entrepreneurship and starting a nonprofit. She might tell her counterpart from Kampala about the intractable nature of the legislative branch, the long history of gun culture in this country and its passionate defenders, the complexity of mental illness and its treatment. She would perhaps mention 
the added complication of agitating for change as an outsider. But if you ask that same 22year-old American about some of the most pressing problems in a place like Uganda rural hunger or girls' secondary education or homophobia — she might see them as solvable. Maybe even easily solvable (Martin, 2016).

The above example and reflection serve as an illustration of how the 'social' in social entrepreneurship is not a neutral feature of what social entrepreneurs do. Similarly, emerging research from McMullen and Bergman (2017) discusses the paradoxical view that social entrepreneurs become so embedded in the problem that they begin to demand an emotional and counterproductive return on their efforts. Dey and Lehner (2017) suggest it is merely a hedonistic journey for some entrepreneurs. There are similar patterns throughout the literature and whilst there is a general consensus that social entrepreneurs attempt to solve social problems there is a lot less emphasis on the meaning of the 'social' within that (Stevens, Moray, and Bruneel, 2015). However, since Zahra et al. (2009) discussed the need for further research that critically explores how different individuals approach social problems, empirical exploration and theoretical understanding of the 'social' in social entrepreneurship remains limited.

\section{Sensemaking notions of social justice}

Given our interests in understanding social entrepreneurship practices and how such actors conceive of social problems, we focused on a range of literature that articulates what such problems look like and how entrepreneurs have identified particular solutions to them (e.g. Pless, 2012; Santos, 2012; Zahra et al., 2009). Sen's (2009) notion of arrangement and realization perspectives holds promise for gainer a deeper understanding of our theoretical and practical dilemma, suggesting a need to re-think the nature of social problems, the solution space for them and their link with social justice.

Underlying the prior discussion and observation are varying notions of social justice. 
Broadly defined, social justice refers to consideration of 'how the good and bad things in life should be distributed amongst the members of a society' (Miller, 1999: 1). Individuals tackling social problems use 'evaluative systems' which are rooted in varying social justice theories which represent a 'plurality of unbiased principles' that can 'have quite distinct manifestations' (Sen, 1999: 13). In doing so, social entrepreneurs must conceive of a system of cooperation in which political and social institutions fit together in a manner that adheres to a series of primary goods - basic rights, liberties, freedoms, income and wealth, amongst others (Rawls, 2009).

Sen (2009) delineates between two social justice approaches which helps outline our argument: arrangement or realization perspectives. Sen (2009) uses the language of Sanskrit to emphasize the distinction between these approaches to justice as being 'niti' and 'nyaya'. The term niti is concerned with propriety and 'behavioural correctness' of people whereas nyiyi relates to actual realized justice in a complex world. In this sense, the role of organizations, rules and institutions (niti) should be seen within their broader societal context and be more inclusive to the emergent world which is inherently complex (nyaya). The arrangement perspective (niti) represents an institutional approach to social justice that considers the potential - and dreams about its achievement - for complete 'fairness'. Sen (2009) describes this position as 'transcendental institutionalism' which 'concentrates its attention on what it identifies as perfect justice' (p.5) through institutional arrangements. The transcendental arrangement view focuses primarily on getting the institutions and rules right with the assumption that the necessary institutions lead to a certain set of behavioural outcomes (e.g. for beneficiaries). However, this perspective says less about the reality of the 'world that actually emerges' (p.20) under these conditions or the 'actual behaviours of people and their social interactions' (p.6) within a complex and sometimes contradictory institutional setting.

Let us illustrate the differences between transcendental institutionalism and realization by discussing two examples within the field of social entrepreneurship: microfinance 
organisations and clean water transportation. On one hand, the transcendental institutionalism perspective places institutions and their development at the centre of promoting justice for certain groups. For example, this is reflected in the microfinance phenomena pioneered by notable social entrepreneur Muhammad Yunus (1999) where the absence of financial institutions to serve micro-entrepreneurs is seen as the primary reason for perpetual poverty. In this transcendental logic, the most just path for solving the social problem (lack of access to financial services) is to correct a market or government failure by establishing some new organization that does this (microfinance institutions). However, as Sen (2009) argues, such a view makes fundamental assumptions about how people (i.e. beneficiaries) then live in these new institutional arrangements (McMullen, 2011) with a large body of research documenting the mixed experiences of microfinance recipients (Chliova, Brinckmann, and Rosenbusch, 2015; Kimmitt and Muñoz, 2017).

Therefore, this institutional perspective remains a strong theoretical lens for explaining how social entrepreneurs recognise entrepreneurial opportunities and how social problems are framed by institutional actors (Wadhwani, 2018). Social problems are typically considered a consequence of market-failure, whereby market institutions do not optimally provide efficient outcomes for individuals (Austin et al., 2006). The notion of the institutional void (Khanna and Palepu, 1997) or institutional 'imperfection' (Roth and Kostova, 2003) have been prominent in the literature. Prior research has highlighted the link between institutional weakness and property rights (De Soto, 2000); the lack of consumer empowerment and, inadequate product design in developing markets (Prahalad and Hart, 2002). The solution to all of these problems seems to revolve around the idea that the poor require credit through financial institutions to unlock their ability to act entrepreneurially or to consume (Shahriar, Schwarz, and Newman, 2016); an argument that has not been criticized enough in scholarly work (Kimmitt and Muñoz, 2017). Indeed, McMullen and Bergman (2017) argue that this institutional view produces 
social paradoxes whereby social entrepreneurs seek gratitude for 'patching-up' institutional voids.

On the other hand, in a realization perspective, the institutional focus is less prominent with social problems and entrepreneurship seen in a much more localised collaborative sense. For example, standing in contrast to our previous Play Pumps example, Wello Water and their 'Water Wheel' were co-developed with villagers as a durable solution to safe and clean water storage (Wello Water, 2018). This is similar to Corner and Ho (2010), who discuss 'collective action' between communities and entrepreneurs in the opportunity development process. The concept of social bricolage similarly emphasises the importance of stakeholder participation in thinking about social problems and solutions (Di Domenico et al., 2010). This perspective follows the view that the relationship between a social entrepreneur and a problem is emergent, organic and effectuated through relationships and actions (Akemu, Whiteman, and Kennedy, 2016). In a realization perspective, social entrepreneurs may solve institutional failures (e.g. access to safe water) but their assessment of the social problem concerns how individuals (beneficiaries) respond to a potential solution and the learning this generates.

This brings to our attention the potential micro-level processes that may underpin how social entrepreneurs make sense of situations in which 'social problems' are judged to have been discovered and acted upon. Dacin et al. (2011) emphasize that sensemaking and sensegiving theories are required for theoretical development and needed to move beyond the idealized 'heroic' types that exist in the literature. Sensemaking informs us that meanings of situations materialize inform, propel action and/or constrain identities (Weick et al., 2005). It is the process through which people work to understand issues, situations and events that seem ambiguous or novel such as their understanding of social problems and their solutions (Maitlis and Christianson, 2014; Muñoz and Kimmitt, 2018). However, the literature primarily views this through the classic language of the entrepreneurial process (Perrini, Vurro, and Costanzo, 
(2010) and/or opportunity development (Corner and Ho, 2010) which may not be particularly informative in unpacking the 'social' in social entrepreneurship.

Whilst social entrepreneurs must 'make sense' of their novel situations and create some kind of solution, this must also be communicated to other relevant stakeholders. Sensegiving pertains to the process of attempting to influence the sensemaking and meaning construction of others (Gioia and Chittipeddi, 1991). Giving sense to others through meaningful communication methods has been shown to be an important aspect of how new firms gain support (Cornelissen and Clarke, 2010) such as through narratives and storytelling in the case of social entrepreneurs (Jones, Latham, and Betta, 2008). Therefore, a major task for social entrepreneurs involves sensemaking of the problem space and sensegiving to others about the potential solution to that space. Both involve a new vision for how the social problem can be solved and how it should be communicated to others (Hill and Levenhagen, 1995).

In summary, our review indicated the dominant idealized notions of social entrepreneurship that exist in the literature (Dacin et al., 2011) but also in the context of an emerging cautious perspective. Such a perspective calls into question the neutrality of the term 'social' in social entrepreneurship - the assumption that the way in which social entrepreneurs understand, approach and define the problem they are trying to solve is impartial and thus lacking ideological steering and pre-conceptualised actions. Sen's (2009) ideas suggest that this may have significant implications for understanding the 'social' from a justice perspective (i.e. how social entrepreneurs contribute to the good and bad things in life) and help unpack the aforementioned issue. Therefore, this leads us to ask: how do social entrepreneurs make sense of social problems and develop entrepreneurial practices for tackling such problems?

\section{Methods}

As previously articulated, our view here is that there exists a clear need to challenge the 
assumed neutrality of a 'social problem' within the literature. This has ramifications for understanding the justice outcomes that social entrepreneurs make sense of and give sense to. In consequence, in this study we adopt a qualitative research design drawing specifically on a novel type of inquiry that enables observing how people make sense of social changes and the practices contributing to positive or negative outcomes, namely: Social Justice Inquiry (Johnson and Parry, 2016). This method is closely linked to interpretive qualitative methodologies because of a need for granular detail of how certain actors link their sensemaking and sensegiving practices to the oppressed, disenfranchised or impoverished. Such inquiry should re-orient thinking about how the world changes and bring to the fore how societal practices and institutions enable alternative outcomes (Johnson and Parry, 2016). Fundamentally, social justice inquiry involves adopting a critical stance towards issues of inequality, poverty, privilege and individual rights (Charmaz, 2011).

For our inquiry, we used qualitative research techniques (Gioia, Corley, and Hamilton, 2013) to collect and analyse our data, focusing on the process of recognising, assessing and judging the pertinence of the social problem under consideration. This established procedure for inductive theory-building research aims at increasing the rigour throughout the inductive reasoning process and consequently the confidence in the results and emergent theoretical categories. It equips 'inductive researchers with systematic conceptual and analytical discipline that leads to credible interpretations of data and also helps to convince readers that the conclusions are plausible and defensible' (Gioia et al., 2013: 15).

\section{Case selection}

The sample for this study comprises 15 experienced social entrepreneurs from Chile (Table 1). They were purposively selected from a broader group of socially oriented enterprises who participated in the largest study on the third sector in the country to date. We selected our 
participants following four criteria: self-identification, active involvement in the development of the venture as founder or co-founder, years of trading and unfamiliarity of the context of operation. First, we selected those entrepreneurs who agreed with the following statement: 'A social enterprise is a business with a social mission, where profit is usually reinvested in the purpose of the business or the communities they serve, instead of maximising the economic return for shareholders and/or owners' (Haugh, 2006; Tracey and Jarvis, 2007). Second, out of this list we selected those who have been actively involved in the development of the business, as sole or co-founder of the social enterprise. Third, we included only those who have been running their social businesses for a relevant period of time but have not yet moved to a managerial stage (i.e. between one and four years). Finally, we needed a sample of social entrepreneurs in the process of entering and/or starting operations in unfamiliar 'novel' social or geographical locations.

These selection criteria draw on the following rationale: first, self-identification and active involvement enable us to capture the perception and practices articulated by the social entrepreneur at the individual level, which is central to our examination of sensemaking and sensegiving processes. Second, setting the temporal window in between one and four years of trading enables us to capture entrepreneurial practices rather than managerial routines. Our final criterion 'entering an unfamiliar context' relates to our need to capture entrepreneurs 'accessing a new social space' and 'making judgements' about new information regarding the social problem as it becomes available to them. We did so by focusing on social entrepreneurs starting their businesses in a different geographical area as they were trying to solve problems away from their place of residence. If the social context were known to the entrepreneur, the definition and assessment of pertinence of the social problem would have relied on personal experience and previous knowledge derived from living in the area. Our approach is consistent with previous sensemaking studies in social entrepreneurship (e.g. Holt and Macpherson, 2010; 
Cornelissen, Clarke, and Cienki, 2012) which, as ours, are focused on situations and events that seem ambiguous or novel. In Table 1, we provide a summarised view of the social entrepreneurs we included in our study and the novel spaces they have entered with their ventures.

---Insert Table 1 about here---

\section{Data collection}

Data were collected using semi-structured interviews. These were conducted between May and July 2016. The interviews lasted between 50 and 70 minutes. These were recorded and transcribed in Spanish and then translated into English by one of the authors of this study, who is a native Spanish speaker. This is in line with current practice (e.g. Temple and Young 2004; Van Nes, Abma, Jonsson, and Deeg, 2010) as it enables the researchers to retain meanings and context-specific elements. The interview guide was divided into five sections with 19 guiding questions, all related to decisions and circumstances during early stages of development. These sections are: history of the venture, expected beneficiaries, and previous professional and personal experience; social mission and identity; search and acquisition of resources; relationship with broader institutional environment; growth aspirations and perceived impact. We complemented interview data with secondary sources of evidence including website materials, media (both newspaper and video), strategy documents, company reports (when available), and other social accounts. This enabled us to triangulate evidence and corroborate founders' accounts. The cases are reported in the paper anonymously using descriptive terms from the organisation to give a sense of their general activities.

\section{Data analysis}

Our methodological approach required the delineation of first-order codes, categories, and aggregate constructs as the researchers worked iteratively between emerging dimensions and 
the interview data. Drawing on the work of Gioia et al. (2013) and previous abductive inferential research (e.g. Walsh and Bartunek, 2011; Akemu et al., 2016), our data analysis relied on an inductive-then-deductive analytical procedure, which is particularly relevant when emerging constructs and relationships that are not yet well articulated in the literature.

In a first stage, we used exploratory coding to reveal reoccurring elements emerging as the social entrepreneurs were identifying and reflecting on the problems they wanted to solve. This led to the development of first-order codes. We identified several conflicting patterns across the interview data, such as 'problem is institutionally defined and clear' vs. 'problem is made sense of ex-post and is opaque', which suggested that a bifurcation in how social entrepreneurs make sense of the problems they seek to resolve. We noticed that this bifurcation remains consistent as the entrepreneurs define the solution space and elaborate social value as well as in the communication of such value (sensegiving). Table 2 presents an illustration of our inductive analysis leading to the bifurcation as shown in the opposite outer columns.

\section{---Insert Table 2 about here---}

While first-order codes were developed inductively, categories and constructs were crafted by means of abductive analysis: i.e. looking at, arranging and reflecting on the codes through the lens of the existing literature on sensemaking, sensegiving and our previously discussed ideas of social justice. In Table 3, we provide an illustration of our abductive work combining inductive inferences and deductive contributions and the abductively-derived categories. This stage-wise analysis (inductive then deductive) helped us better organize and explain what we saw in our interview data and narrow our categorizations.

---Insert Table 3 about here---

As seen in Table 3, a more refined set of conflicting concepts and themes starts to emerge, such as 'conformist problematizing' vs. 'reflective problematizing' in the assessment and 
delineation of social problems, or 'open' vs 'closed parameters of solution space' in the framing of the solution space and definition of problem-oriented solutions. Figure 1 provides a summarized view of the data structure, assisted by abductive analysis (Table 3), leading to our results, particularly the delineation of the sensemaking and sensegiving bifurcation. By focusing on the conceptual bifurcation through the inductive-then-deductive procedure, we were able to differentiate two approaches representing two distinct ways (Types 1 and 2 in Figure $1^{1}$ ) whereby social entrepreneurs define, make sense of and give meaning to the social problems they seek to tackle, which we explain in detail in the following section.

---Insert Figure 1 about here---

\section{Research findings}

In our endeavours to uncover how social entrepreneurs determine what is a pertinent social problem and the associated practices, we identify two broad dimensions associated with the sensemaking and sensegiving that relate to Sen's (2009) notion of arrangement and realization approaches. This is augmented with prior theory in our abductive analysis. In the first instance, we highlight how entrepreneurs specify what justice is, by problematizing the space in two distinct ways: conformist and reflective. Secondly, we identify how perceived solutions to these problems remain open or closed to change, development and iteration. Lastly, we emphasise the legitimizing practices of social entrepreneurs as they engage their ideas and solutions with relevant stakeholders. In the following, we present these dimensions with their sub-components using raw data from our interviews, which can be found as exhibits in Table 4.

---Insert Table 4 about here---

\footnotetext{
${ }^{1}$ Dotted line in type breaking indicates non-observed inference.
} 


\section{Problematizing: defining problem space}

How do social entrepreneurs make sense of the social problem they seek to resolve? We observe sensemaking by social entrepreneurs concerning conformist problematizing and reflective problematizing that relate to and enhance our theoretical notions of differing types of social justice as postulated by Sen (2009). Whilst these categories relate to the broad narrative of differing perceptions of social justice, we are able to enrich these through our empirical examples.

Conformist problematizing. The challenges of social problems are conveyed by their sheer complexity. Our empirical analysis demonstrates conformist problematizing, which refers to how social entrepreneurs simplify and rationalise the nature of a social problem through its unquestionable presence. In line with an arrangement-driven perspective, we observe how the social problem is defined by institutions, seemingly self-evident to the entrepreneur and identified ex ante (i.e. taken as given).

The view of transcendental institutionalism is that social justice concerns the development or re-arrangement of institutions. This practice is reflected in how social entrepreneurs make sense of social problems, by defining social problems according to institutional weaknesses. Public spaces designs and builds new public spaces to improve well-being. These include skate parks, recreational, sidewalks and other types of spaces [Rodrigo, exhibit 1]. In this context, the entrepreneur makes sense of the social problem through the inherent weaknesses of the institutional context - management capacity amongst local government and their design capabilities. The problem is defined by institutions in the first instance and not by potential users of the public spaces, even though the problems experienced by potential users may be wide and varied.

This simplification of what are likely to be complicated social needs is also demonstrated 
by how the social problem is defined ex-ante, i.e. built on a pre-conceived notion of how the problem should be tackled. Climate and Farming has the idea of tackling how farmers deal with the effects of climate change and, as James explains, specifically variations in levels of rainfall [James, exhibit 2]. In this example, the nature of the social problem is defined ex-ante in the sense that they are trying to solve an agriculture-related problem but have not engaged with those farmers to scope this out. Similarly, the entrepreneur was working with institutional partners - subsidies with government entities - viewing them as their most important set of contacts.

Reflective problematizing. We are also able to identify a qualitatively different specification of justice related to Sen's ideas of a realization-focused approach. This approach has its basis in understanding 'actual behaviours of people and their social interactions'. The idea behind Dental Health is to develop low-cost healthcare services that are affordable to a marginalized population [Arturo, exhibit 3]. In this approach, the social entrepreneur reflects on the social problem by identifying the diverse needs of the population and recognising its evolutionary nature. It focuses on using knowledge gleaned from such conversations to inform the very nature of how it approaches the problem at hand.

In comparison to conformist problematizing, this approach involves constant reflective action, making sense of the problem ex-post and recognising that it is opaque because circumstances are continuously evolving and localities vary in terms of their needs. As such, our observations highlight how social entrepreneurs identify what is a pertinent social problem and the sensemaking processes associated. In one respect, we observe that problems are institutionally defined (Austin et al., 2006) and viewed as being unquestionably present. In contrast, we observe how social entrepreneurs reflect upon their problematizing - building knowledge and ideas through local interactions with the relevant users (beneficiaries). 


\section{Solving: defining solution}

How do social entrepreneurs decide what the most appropriate entrepreneurial practices for tackling their specified social problems are? This leads us to think about the solutions they develop according to their specified notions of social justice. We observe that entrepreneurs can view the solution space to remain either closed or open. In the former, an arrangement focus, the solution to the problem is assumed and is therefore closed to new possibilities. In the latter, realization focus, the parameters of the solution remain open meaning that new ways of solving the ever-changing social problem are considered and enacted.

Closed parameters of solution space. In the development of appropriate solutions, the practices of social entrepreneurs follow the logic of prescribing solutions that are sometimes technical in nature or where the boundaries of the solution space appear taken for granted. Therefore, we observe how entrepreneurs assume the solution to be the appropriate tool and approach needed to change the problematic landscape. Working alongside the requisite institutional actors in University incubators and with local government, Urban agriculture developed the idea of communities being able to grow and cultivate their own produce in community greenhouses. Using Sebastián's prior skills, the solution for this was the development of a technology that allowed for a composter that recycled waste and produced energy [exhibit 4]. In this case, the assumed solution stems from the perceived predictability of how the end users (beneficiaries) would actually interact with the new technology at the community level. Whilst the technology seems to be a solution for a particular technical problem (energy waste and food production) it does not take into account the behavioural characteristics of the communities adopting it.

Similarly, Santiago at small farming developed an online platform that connects farmers with a new set of buyers for their produce. Camila started Indigenous entrepreneurship as a national centre that provides communities with access to resources for entrepreneurial 
development. Fabrication lab, started by Isabella, provides collaborative spaces that allows other businesses to develop new technologies to be developed for other local communities. Therefore, we see a consistent distinction between how some social entrepreneurs approach the development of appropriate solutions. In this set of cases, the solutions are assumed and are, by their very nature, more closed to new opportunities. As it resonates within the transcendental view, it is assumed a sufficient solution to a particular institutional problem.

Open parameters of solution space. In a realization framework, however, we observe a different set of actions according to nuances in local practices. As such, the solution space remains open to change and development within the same logic of social justice. Started by Juan, Entrepreneurship support is a programme that assists entrepreneurial development and social innovation across disadvantaged communities in the country. However, the programmes they run at community level are all adapted and refined before anything is formally established there [exhibit 5].

Therefore, the approach to solution development here is inherently open because it acknowledges that each community is different and therefore the solution has to be too. This is reflected in the wide variety of positive outcomes that Juan experiences. Given that these entrepreneurs are consistently reflective of the problem at hand then the proposed solutions will similarly acknowledge the problem's complex nature. In this respect, social entrepreneurs acknowledge and recognise the boundaries of their solutions. They are refined, iterated and developed through conversations and observations at the local level. It recognises diversity across localities and the diverse elements of communities, and that the solution may not be appropriate in every context, in fact, it is unlikely to be. Thus, we see again social entrepreneurs invoking a realization approach - through the gradual amelioration of prevailing injustices rooted in the practicalities of actual beneficiary behaviour - in the development of their solution. 


\section{Evoking: communicating social value}

Although social entrepreneurs must make sense of the problems and solutions that comprise their respective organisations, they must also engage in sensegiving, which involves more fundamentally communicating with relevant stakeholders. Our findings similarly highlight how these sensegiving practices play out across arrangement and realization perspectives. In the former, we identify how social entrepreneurs look to align themselves with key institutional actors for the purposes of legitimising their organisations. In the latter, social entrepreneurs adopt a more collaborative approach with members of local communities as well as institutional actors.

Aligning. Sensegiving in this context pertains to how social entrepreneurs communicate their organisations to others. Our findings highlight that they adopt an approach that seeks to align themselves with key institutional actors. This is consistent with the idea that their organisations stem from a need to solve an institutional problem and as such, they must legitimise their actions in this space. Culture and arts provide cultural activities to young people in the music and arts [Gustavo, exhibit 6]. The development of the business is firmly rooted in the approval of other institutional actors and provided a central impetus to what they decide to offer as an organisation - 'playing with the social issue' - gaining notable approval from the local municipality. As such, this approach, with its institutional basis, requires sensegiving practices by social entrepreneurs who are looking to align themselves with such actors.

This alignment represents a process of legitimisation, which is similarly reflected in how they approach interactions with users (beneficiaries). In contrast to our other subset of entrepreneurs, we observe that this seems like much more of a validation process rather than a set of meaningful interactions. For example, Culture and ecology delivers educational programmes around issues of education and environmental sustainability [Sofia, exhibit 7]. As 
this example demonstrates, there is clearly an engagement with users (beneficiaries) but it primarily has a validation or feedback function ex-post. This offers another source of legitimacy for the organisation to the communities in which their services are offered. It is consistent with the idea of sensegiving here as a process of alignment as essentially legitimising with relevant stakeholders.

Collaborating. In contrast, we observe that sensegiving can often be more collaborative in nature and represents an internalized ideal and value of the entrepreneur. Here we see the social entrepreneur engaging in consistent dialogue with users to sensegive their ideas and establish a platform for mutual learning. In comparison, we see very little external legitimacy building activities from this subset of entrepreneurs, their main sensegiving activities involves their relationships with users. However, where relationships are developed with institutional actors, they do adopt a similar mutual learning function [Juan, exhibit 8].

In summary, across our sample of social entrepreneurs we see qualitatively different approaches to sensegiving strategies. These sensegiving processes reiterate the role of institutions and their respective key actors as something that social entrepreneurs seek to align themselves with. In contrast, social entrepreneurs can also seek out very few institutional relationships and focus their efforts solely on collaborative community-level interactions.

\section{Type-breaking: re-orienting Justice}

We also identified two stand out cases which shifted between different approaches according to our two notions of social justice which appear to emerge as a result of sensebreaking, defined as 'the destruction or breaking down of meaning' (Pratt 2000, p. 464). Indigenous entrepreneurship operates entrepreneurial development programmes that focus on skills and education to assist individual movements out of poverty. Initially, the solution for the social problem was carefully defined around a market need, and then developed as something which 
can work in conjunction with a national policy agenda and the associated funding streams [Camila, exhibit 9].

As shown in Figure 1, this sensebreaking completely reoriented how they viewed problems, constructed solutions and sensegiving conversations. They had previously followed institutional definitions of social problems and associated solutions before recognising their lack of local applicability and emphasises the shift - in social justice terms - from general to place-specific problems. In our sample, we only identify this sensebreaking within two of our cases but it does highlight that arrangement (Type 1) and realization (Type 2) approaches may not be path dependent. Although not discovered within our sample, it similarly raises the proposition of whether social entrepreneurs can move from realization to arrangement approaches. Indeed, this seems quite plausible as localized social innovations may gain traction, more widespread adoption and subsequently no longer benefit from having embedded place-specific knowledge.

\section{Discussion}

In this paper, we set out to explore how social entrepreneurs make sense of the social problem at hand and develop entrepreneurial solutions for tackling such problems. Even though social entrepreneurship would appear to have profound implications for improving the well-being of the social contexts in which it operates (Santos, 2012), a deeper examination on the practice of social entrepreneurship and the actual implications of current approaches is virtually inexistent. Despite having previously speculated about this behaviour (Zahra et al., 2009), there are very few empirical explorations of this debate. It seems that practice and theory have overemphasized the role of rules and institutional arrangements as an approach to justice (e.g. Mair and Marti, 2009), rather than focusing on improving the circumstances co-dependently with people within those institutional settings. 
We do not mean to imply that an institutional view is normatively incorrect or disembedded from the needs of the community, but it may not always be consistent with what the members of a particular community value and need (Sen, 1999). In this paper, we offer two qualitatively different approaches to thinking about social justice and the ethical practice of social entrepreneurship. Developing Sen's (2009) theory, it indicates the likelihood that the two approaches produce differing social justice outcomes. Drawing on the two types identified, as well as the type-breaking instances, in Figure 2 we introduce our theorised 2-type social sensemaking model, abducted from the data and literature, pertaining to the appreciation and assessment of circumstances and the differing problem/solution combinations emerging from alternative ontological views of what constitutes a social problem. Our model draws on a typology-based style of theorizing, explaining the fuzzy nature of social sensemaking and logically combining the different building blocks into two coherent types (Cornelissen, 2017).

---Insert Figure 2 about here---

Firstly, the model provides a comprehensive view of two alternative ways in which social entrepreneurs distinctively define what a social problem is [problematizing], define its pertinence and consider solutions [solving], and communicate it [solving - evoking], i.e. sensemaking and sensegiving. Secondly, it empirically derives the structure and the building blocks for each type taking into account alternative views of social justice. Whereas Type 1 is formed by conformist problematizing, closed parameters and aligning, Type 2 is constructed upon reflective problematizing, open parameters and collaborating. In doing so, it enables an integrative and at the same time more fine-grained understanding of social entrepreneurship practices pertaining to the different ways in which social entrepreneurs appreciate and assess social circumstances (normally social problems), make and commit to actions. Linked to each building block, we provide a number of corollary insights that flows from the model and expands the understanding of the process. 
Figure 2 also highlights a sensebreaking activity (indicated by curved arrows) that reorients views of justice, transforming an institutionally driven process into one that reconsiders the social problem as emergent and begins to integrate practices such as co-creation and dialogue. We identified that this results in cases reorienting justice from Type 1 to emulate Type 2, which we empirically identify as a type-breaking instance and reorientation of social value, which could eventually lead to a third social sensemaking type (Type 1a). We wonder whether the opposite, Type $2 \mathrm{a}$, is possible, and if so, under what conditions an entrepreneur will reorient justice in the opposite direction: from a realization to an arrangement-based perspective. In Figure 2, this is represented by the dashed curved arrows as a deductively derived non-observed inference. From our point of view, this may be unlikely to occur and we can only speculate on that change process by logically exploring counterfactuals. Such a speculation may involve thinking about the effects of scaling as successful localized solutions are embraced and institutionalised. It is important to note that our proposed typological model, while visually linear, does not seek to imply that there is causal linearity in the way social entrepreneurs appreciate social problems and make decisions in reaction to them. It simply provides an organised and multi-ontological view of the interplay between social context and individual action and the building blocks of such interplay, capturing its complexity beyond our current understanding.

\section{Theoretical contributions}

Our paper makes three key theoretical contributions. First, by uncovering two alternative types (and permutations) whereby social entrepreneurs assess, judge, comprehend, embrace, and act upon a particular social problem, our work delineates a number of unique sensemaking, sensegiving and sensebreaking activities. This directly responds to the call by Dacin et al. (2011) to draw from theories of sensemaking and sensegiving in the context of social 
entrepreneurship. Thus, through Figure 2, we provide a more comprehensive explanation of the opportunity development process leading to social value creation, which involves the pursuit of solutions to neglected problems with positive externalities (Santos, 2012). By articulating problematizing, solving and evoking as sensegiving categories, we explain the relationship between complex social problems and solutions beyond the institutional realm, extending current literature on opportunity recognition in social entrepreneurship. This is relevant since the black box of social value creation seems to still be sustained by the assumption that social problems are institutionally defined (Dorado and Ventresca, 2013), which has hidden away the potential differences (Type 1 and 2) for understanding the 'social' in social entrepreneurship practice.

We show that acting on complex social problems does not necessarily require or is about distinct institutional arrangements. Through the lens of the social entrepreneur (Type 2 specifically), the social problem may not look like an institutional one. Social entrepreneurs can indeed engage in action based on their own understanding of the context, and institutional arrangements may be even rendered superfluous. They may end up solving institutionally defined problems but institutions may not be embedded into their practices explicitly. Our distinction opens up a new avenue for understanding how opportunities, derived from perceived social problems, are recognised and pursued in social entrepreneurship. Explanations of the process leading to social value creation still seem to rely on distant factors that overemphasise predominately cognitive predispositions such as motivation and self-efficacy (e.g. Yitshaki and Kropp, 2016; Clark et al., 2018). These studies, under the assumption of immutability, fail to recognise the many alternative ways in which social value can be created. This can only visible when the sensemaking and sensegiving process is unboxed. Our study explains how this works. Otherwise, we argue, explanations of how opportunities are recognised and developed in social entrepreneurship will remain obscure, relying on simplified 
variance-based explanations.

We also show that seeing and framing the problem is not enough and that acting requires other complementary sensemaking and sensegiving (and even sensebreaking) activities, exposing this way the current narrow view of how social entrepreneurs define social problems. The two alternative types identified and subsequently theorised in Figure 2 enable a finegrained multi-ontological understanding of the different ways in which social entrepreneurs come to appreciate and assess the social circumstances surrounding their efforts, articulate decisions and practices. We believe that by doing so we respond effectively to a recent call from Shaw and de Bruin (2013) and Mair et al. (2012) regarding the need for a deeper examination and theorisation of social entrepreneurship practices. We do so by connecting three key areas previously identified by Pless (2012): (1) the social needs and constituencies targeted, (2) the mission of the social entrepreneur and (3) the processes and resources used. In Figure 2, these are evidenced in the alternative ways in which social entrepreneurs (1) explore and define the problem space, (2) make interpretations and judgments regarding the social problem they seek to resolve and the subsequent declaration of intent, and (3) delineate the solution space, evolve business solutions and engage in activities to bring this closer to beneficiaries.

Our second contribution pertains to the assumed intentionality of social entrepreneurs. We uncover the different sensemaking, sensegiving and sensebreaking processes in relation to how social entrepreneurs interact with and respond to social problems. In doing so, we provide a more fine-grained explanation of the processes underlying innovative and entrepreneurial activity for social purposes. This expands the work of Luke and Chu (2013) in their efforts to differentiate social entrepreneurship from social enterprise. At the same time, our work provides a cautious view of the predominant view of the intentions underlying social entrepreneurs, i.e. they provide solutions to social problems (Dacin et al., 2011), which is 
tautological and problematic (Santos, 2012). Accompanying Santos's (2012) critique, we argue that the (good) intentions of social entrepreneurs can no longer be taken for granted due to the risks involved in making unsubstantiated evaluations based on ideas of how the world should work (i.e. notions of social justice).

While Figure 2 does not show us disastrous outcomes, it does point us to recognize potentially assumed practices based on Sen's theoretical positioning. We suspect that sensebreaking activities emerge as a natural response to tensions derived from clashes between how the entrepreneur thought the world should work and how it actually works after experiencing the problem. In doing so we avoid normative classifications of what is social and what is not, contributing to the work of Santos (2012). Aligned with our previous argumentation, we do not seek to imply that an institutional view is normatively wrong but that it may not always be consistent with complex place-specific needs. Echoing Montgomery et al. (2012), our results also stress the relevance of entrepreneurs being embedded in their context and using this to co-create solutions with that context.

The fact that the definition of social problems by institutional actors may differ from that of the intended beneficiaries of socially oriented actions invites us to reflect on the adequacy of our current theoretical frameworks. So far, most of our work has been institutionally dependent. Sen's perspective, on the contrary, suggests that social justice processes and outcomes should not be taken for granted, nor should be the (presumed) good intentions of our subjects of interest. By drawing on the work of Sen, we believe that our work provides better theoretical background for exploring and explaining practices and social justice in entrepreneurship. It also gives us a basis to explore the potential dark sides of social entrepreneurship, because whilst there are known anecdotal cases (e.g. Playpumps) we have very little empirical evidence about this phenomenon. These complex issues need to be acknowledged and addressed if theory and practice are to move forward. 
Our final contribution pertains to the (so far blurry) links between social entrepreneurship practice and social justice theories. Since the 'social' in social entrepreneurship seems to hold the promise for a better future, this practice has been assumed socially just, but so far we have not gone beyond ethical decision-making and normative frameworks. This is problematic because it leaves us with the daunting task to subjectively assign a normative connotation to the word social (Santos 2012) every time we are to observe and analyse the practices of social entrepreneurs. As a start, the theoretical language of Sen (2009) helps better understand realworld complexity. We argue that this is much needed to overcome the idealized conceptions that have characterised social entrepreneurship theory and practice so far. Through our findings, our work responds to recent calls stressing the 'need for greater reflexivity and critical consideration of socially entrepreneurial practices which extends to evaluate the impact and effectiveness of social entrepreneurship and social innovation in developing solutions relevant to the multifaceted nature of social problems' (Shaw and de Bruin, 2013: 743).

\section{Limitations and future research}

There are limitations to our work as well as opportunities for further research. One concern relates to the use of retrospective self-reports as a source of primary data as it may trigger a number of memory biases. We mitigated this potential issue in two stages of the study: data collection and data analysis. First, we framed the interview guide in a way to elucidate the structure of the entrepreneurial journey and the chronology of events from the identification of the social problem to the development of solutions and interactions with stakeholders. Reconstructing the history of the venture at the beginning of the interview was instrumental in increasing the validity of our (time-bounded) inferences. During the data analysis stage, we carefully triangulated the data comparing the entrepreneurs' memories with data from venture documents (e.g. business plans, marketing material) and publicly available documents (e.g. 
media articles, twitter posts, etc.).

Second, the method we used to select social entrepreneurs for our study assumes that those agreeing with our definition are individuals driven by a given set of values and intentions (i.e. a desire to solve social problems). However, the actual degree of 'altruism' or value-driven behaviour cannot be fully captured and factored in. While we followed procedures to ensure the presence of an area of homogeneity across the sample, i.e. individuals sharing background characteristics, we can never be completely certain of the full range of (sometimes hidden) factors driving people's judgements and decisions. We acknowledge these issues and clarify that our inferred typologies are bounded by those conditions. This certainly opens up opportunities for future research. Although we opened the black-boxed process of social value creation, new questions and black boxes emerge, for example, why do some individuals make decisions leading to Type 1 social sensemaking and not the other? What tensions and conflicts do emerge at the time one or the other journey has begun? Alternatively, what tensions exist between social entrepreneurs pursuing the same goals but under different ontological positions?

\section{Concluding remarks}

In this paper, we asked, how do social entrepreneurs make sense of the social problem they seek to resolve and develop solutions for such problems? We identify and elaborate on two qualitatively different approaches (and permutations) aligned with an arrangement transcendental approach or a realization-focused approach. We propose that this provides a much-needed theoretical contribution to the field, which has assumed the neutrality of social problems and practices in social entrepreneurship. In doing so, we hope this provokes further reflections on how social entrepreneurs recognise opportunities for social value creation and contribute to solving prevailing social issues. 


\section{References}

Akemu O, Whiteman G and Kennedy S (2016). Social Enterprise Emergence from Social Movement Activism: The Fairphone Case. Journal of Management Studies, 53(5): 846877.

Alvarez SA and Barney JB (2007). Discovery and creation: Alternative theories of entrepreneurial action. Strategic Entrepreneurship Journal, 1(1-2): 11-26.

Austin, J, Stevenson H and Wei Skillern J (2006). Social and commercial entrepreneurship: same, different, or both? Entrepreneurship Theory and Practice, 30(1): 1-22.

Bacq S and Janssen, F (2011). The multiple faces of social entrepreneurship: A review of definitional issues based on geographical and thematic criteria. Entrepreneurship and Regional Development, 23(5-6): 373-403.

Beer HA and Micheli P (2017). How performance measurement influences stakeholders in notfor-profit organizations. International Journal of Operations and Production Management, 37(9), 1164-1184.

Charmaz K (2011). Grounded theory methods in social justice research. In N. Deniz and Y. Lincoln, eds. The SAGE Handbook of Qualitative Research. Los Angeles: Sage, pp. 359379.

Chliova, M Brinckmann, J and Rosenbusch N (2015). Is microcredit a blessing for the poor? A meta-analysis examining development outcomes and contextual considerations. Journal of Business Venturing, 30(3): 467-487.

Clark, KD Newbert SL and Quigley NR (2018). The motivational drivers underlying for-profit venture creation: Comparing social and commercial entrepreneurs. International Small Business Journal, 36(2): 220-241.

Cohen, B and Winn MI (2007). Market imperfections, opportunity and sustainable entrepreneurship. Journal of Business Venturing, 22(1): 29-49.

Cornelissen JP and Clarke JS (2010). Imagining and rationalizing opportunities: inductive reasoning and the creation and justification of new ventures. Academy of Management Review, 35(4): 539-557.

Cornelissen, JP Clarke JS and Cienki A (2012). Sensegiving in entrepreneurial contexts: The use of metaphors in speech and gesture to gain and sustain support for novel business ventures. International Small Business Journal, 30(3): 213-241.

Cornelissen, J (2017). Editor's Comments: Developing Propositions, a Process Model, or a Typology? Addressing the Challenges of Writing Theory Without a Boilerplate. Academy of Management Review, 42(1): 1-9.

Corner PD and Ho M (2010). How opportunities develop in social entrepreneurship. Entrepreneurship Theory and Practice, 34(4): 635-659.

Dacin, MT Dacin PA. and Tracey P (2011). Social Entrepreneurship: A Critique and Future Directions. Organization Science, 22(5): 1203-1213.

De Soto H (2000). The Mystery of Capital: Why Capitalism Triumphs in the West and Fails Everywhere Else, Basic Books.

Dey P and Steyaert C (2016). Rethinking the space of ethics in social entrepreneurship: Power, subjectivity, and practices of freedom. Journal of Business Ethics, 133(4): 627-641. 
Dey P and Lehner O (2017). Registering ideology in the creation of social entrepreneurs: Intermediary organizations, 'ideal subject' and the promise of enjoyment. Journal of Business Ethics, 142(4): 753-767.

Di Domenico, M Haugh, H and Tracey P (2010). Social bricolage: Theorizing social value creation in social enterprises. Entrepreneurship Theory and Practice, 34(4): 681-703.

Dorado S and Ventresca MJ (2013). Crescive entrepreneurship in complex social problems: Institutional conditions for entrepreneurial engagement. Journal of Business Venturing, 28(1): 69-82.

Estrin, S Mickiewicz T and Stephan U (2016). Human capital in social and commercial entrepreneurship. Journal of Business Venturing, 31(4): 449-467.

George, G McGahan AM and Prabhu J (2012). Innovation for inclusive growth: Towards a theoretical framework and a research agenda. Journal of Management Studies, 49(4): 661683.

Gioia DA and Chittipeddi K (1991). Sensemaking and sensegiving in strategic change initiation. Strategic Management Journal, 12: 433-488.

Gioia, DA Corley KG and Hamilton AL (2013). Seeking qualitative rigor in inductive research: Notes on the Gioia methodology. Organizational Research Methods, 16(1): 15-31.

Grimes, MG McMullen JS Vogus TJ and Miller TL (2013). Studying the origins of social entrepreneurship: compassion and the role of embedded agency. Academy of Management Review, 38(3), 460-463.

Haugh H (2006). Social enterprise: Beyond economic outcomes and individual returns. In Mair, J, Robinson, J and Hockerts, K (Eds.), Social Entrepreneurship (pp. 180-205). Palgrave Macmillan, London.

Hill R and Levenhagen M (1995). Metaphors and Mental Models: Sensemaking and sensegiving in innovative and entrepreneurial activities. Journal of Management, 21(6): 1057-1074.

Holt R and Macpherson A (2010). Sensemaking, rhetoric and the socially competent entrepreneur. International Small Business Journal, 28(1): 20-42.

Johnson CW and Parry DC (2016). Fostering Social Justice through Qualitative Inquiry, Routledge.

Jones, R Latham J and Betta M (2008). Narrative construction of the social entrepreneurial identity. International Journal of Entrepreneurial Behavior and Research, 14(5), 330345.

Khanna T and Palepu K (1997). Why focused strategies may be wrong for emerging markets. Harvard Business Review, 75(4): 41-51.

Kimmitt J and Muñoz P (2017). Entrepreneurship and financial inclusion through the lens of instrumental freedoms. International Small Business Journal, 35(7): 803-828.

Luke B and Chu V (2013). Social enterprise versus social entrepreneurship: An examination of the 'why' and 'how' in pursuing social change. International Small Business Journal, 31(7): 764-784.

Lumpkin GT, Bacq S and Pidduck RJ (2018). Where Change Happens: Community- Level Phenomena in Social Entrepreneurship Research. Journal of Small Business Management, 56(1), 24-50. 
Mahoney J (2000). Path dependence in historical sociology. Theory and Society, 29(4): 507548.

Mair J and Marti I (2009). Entrepreneurship in and around institutional voids: A case study from Bangladesh. Journal of Business Venturing, 24(5): 419-435.

Mair J and Marti I (2006). Social entrepreneurship research: A source of explanation, prediction, and delight. Journal of World Business, 41(1): 36-44.

Mair, J Battilana J and Cardenas J (2012). Organizing for society: A typology of social entrepreneuring models. Journal of Business Ethics, 111(3): 353-373.

Maitlis S and Christianson M (2014). Sensemaking in organizations: Taking stock and moving forward. The Academy of Management Annals, 8(1): 57-125.

McMullen JS (2011). Delineating the domain of development entrepreneurship: A marketbased approach to facilitating inclusive economic growth. Entrepreneurship Theory and Practice, 35(1): 185-193.

McMullen JS and Bergman BJ (2017). Social entrepreneurship and the development paradox of prosocial motivation: A cautionary tale. Strategic Entrepreneurship Journal, 11(3): 243-270.

McMullen JS and Bergman BJ (2018). The promise and problems of price subsidization in social entrepreneurship. Business Horizons.

Miller D (1999). Principles of social justice. Harvard University Press.

Montgomery, AW Dacin PA and Dacin MT (2012). Collective social entrepreneurship: Collaboratively shaping social good. Journal of Business Ethics, 111(3): 375-388.

Moss, TW Short JC Payne GT and Lumpkin GT (2011). Dual identities in social ventures: An exploratory study. Entrepreneurship Theory and Practice, 35(4): 805-830.

Martin C (2016). Western do-gooders need to resist the allure of 'exotic problems'. The Guardian. Available at: http://www.theguardian.com/global-development-professionalsnetwork/2016/apr/23/western-do-gooders-need-to-resist-the-allure-of-exotic-problems

Muñoz P and Kimmitt J (2018). Entrepreneurship and the rest: The missing debate. Journal of Business Venturing Insights. 9: 100-106.

Peredo AM and McLean M (2013). Indigenous development and the cultural captivity of entrepreneurship. Business and Society, 52(4): 592-620.

Perrini, F Vurro C and Costanzo LA (2010). A process-based view of social entrepreneurship: From opportunity identification to scaling-up social change in the case of San Patrignano. Entrepreneurship and Regional Development, 22(6): 515-534.

Pinch T and Bijker W (1984). The social construction of facts and artefacts: or how the sociology of science and the sociology of technology might benefit each other. Social Studies of Science, 14(3): 399-441.

Pless NM (2012). Social entrepreneurship in theory and practice-An Introduction. Journal of Business Ethics, 111(3): 317-320.

Prahalad CK and Hart SL (2002). The Fortune at the Bottom of the Pyramid, Strategy and Business.

Pratt MG (2000). The good, the bad, and the ambivalent: Managing identification among Amway distributors. Administrative Science Quarterly, 45(3): 456-493. 
Rawls J (2009). A theory of justice: Revised edition. Harvard University Press.

Hlady Rispal M and Servantie V (2017). Business models impacting social change in violent and poverty-stricken neighbourhoods: A case study in Colombia. International small business journal, 35(4), 427-448.

Roth K and Kostova T (2003). Organizational coping with institutional upheaval in transition economies. Journal of World Business, 38(4): 314-330.

Santos FM (2012). A positive theory of social entrepreneurship. Journal of Business Ethics, 111(3): 335-351.

Saunders S and Borland R (2013). Marketing-driven philanthropy: the case of PlayPumps. European Business Review, 25(4): 321-335.

Sen A (1999). Development as Freedom, Oxford University Press, USA.

Sen A (2009). The Idea of Justice, Cambridge: Harvard University Press.

Shahriar, A Schwarz S and Newman A (2016). Profit orientation of microfinance institutions and provision of financial capital to business start-ups. International Small Business Journal, 34(4): 532-552.

Shaw E and de Bruin A (2013). Reconsidering capitalism: the promise of social innovation and social entrepreneurship? International Small Business Journal, 31(7): 737-746.

Short, JC Moss TW and Lumpkin GT (2009). Research in social entrepreneurship: past contributions and future opportunities. Strategic Entrepreneurship Journal, 3(2): 161194.

Stephan, U, Patterson, M Kelly C and Mair J (2016). Organizations driving positive social change: A review and an integrative framework of change processes. Journal of Management, 42(5): 1250-1281.

Stevens, R Moray N and Bruneel J (2015). The Social and Economic Mission of Social Enterprises: Dimensions, Measurement, Validation, and Relation. Entrepreneurship Theory and Practice, 39(5): 1051-1082.

Suddaby, R Ganzin M and Minkus A (2017). Craft, magic and the re-enchantment of the world. European Management Journal, 35(3): 285-296.

Temple B and Young A (2004). Qualitative Research and Translation Dilemmas. Qualitative Research, 4(2): 161-178.

Tracey P and Jarvis O. (2007). Toward a theory of social venture franchising. Entrepreneurship Theory and Practice, 31(5): 667-685.

Van Nes, F Abma T Jonsson H and Deeg D (2010). Language differences in qualitative research: is meaning lost in translation? European Journal of Ageing, 7(4): 313-316.

Wadhwani RD (2018) Poverty's monument: Social problems and organizational field emergence in historical perspective. Journal of Management Studies.

Walsh IJ and Bartunek JM (2011). Cheating the fates: Organizational foundings in the wake of demise. Academy of Management Journal, 54(5): 1017-1044.

Weick, KE Sutcliffe KM and Obstfeld D (2005). Organizing and the process of sensemaking. Organization Science, 16(4): 409-421.

Wello Water. (2018) Wello Water Press Kit. Available at: http://wellowater.org/pdfs/press_kit.pdf (Accessed 27th March 2018) 
Yitshaki R and Kropp F (2016). Motivations and opportunity recognition of social entrepreneurs. Journal of Small Business Management, 54(2): 546-565.

Yunus M (1999). Banker to the Poor. London: Aurum.

Zahra, SA Rawhouser HN Bhawe N Neubaum DO and Hayton JC (2008). Globalization of social entrepreneurship opportunities. Strategic Entrepreneurship Journal, 2(2): 117-131.

Zahra SA Gedajlovic E Neubaum DO and Shulman JM (2009). A typology of social entrepreneurs: Motives, search processes and ethical challenges. Journal of Business Venturing, 24(5), 519-532.

Zenios S Denend L and Sheen E (2012) PlayPumps International: Gaining User Buy-In Global Health Innovation Insights. Stanford GSB. 


\section{Tables and Figures}

Table 1 provides details of the organisations and their areas of work

\begin{tabular}{|c|c|c|c|}
\hline Entrepreneur & Profile & Organisation & Description and novel space \\
\hline Gustavo & $\begin{array}{l}\text { Rock musician } \\
\text { and performer }\end{array}$ & Culture and arts & $\begin{array}{l}\text { Culture and arts seeks to make a positive social impact by combining and promoting artistic development and } \\
\text { healthy living. It works with children in school age and their families in Arica (2,000 kilometres from where } \\
\text { Gustavo lives) combining ancient traditions (e.g. Chincorro), therapy (cognitive psychology and } \\
\text { psychopedagogy support) and nutrition. }\end{array}$ \\
\hline Sofia & $\begin{array}{l}\text { Visual artist and } \\
\text { sculptor }\end{array}$ & Culture and ecology & $\begin{array}{l}\text { Culture and ecology offers educational programmes to children living in vulnerable communities, combining } \\
\text { innovation, technology and permaculture. It does so by means of workshops and film festivals for poor } \\
\text { communities living in rural areas, } 150 \text { kilometres from where Sofia lives. Poor communities have no access to } \\
\text { these knowledge areas. }\end{array}$ \\
\hline Isabella & $\begin{array}{l}\text { Architect and real } \\
\text { estate developer }\end{array}$ & Fabrication lab & $\begin{array}{l}\text { Fabrication lab provides a collaborative space within a vulnerable area aimed at delivering training and } \\
\text { promoting the development of technological innovation. It is located in Antofagasta, 1,300 kilometres from } \\
\text { where Isabella lives. }\end{array}$ \\
\hline Camila & $\begin{array}{l}\text { Business and } \\
\text { management }\end{array}$ & $\begin{array}{l}\text { Indigenous } \\
\text { entrepreneurship }\end{array}$ & $\begin{array}{l}\text { Indigenous entrepreneurship provides entrepreneurship support and training to indigenous communities living } \\
\text { in extreme poverty. The social venture originated from an assignment in an undergraduate entrepreneurship } \\
\text { course } 900 \text { kilometres from the area of operation and where Camila lives. }\end{array}$ \\
\hline James & $\begin{array}{l}\text { Molecular } \\
\text { biologist }\end{array}$ & $\begin{array}{l}\text { Climate and } \\
\text { farming }\end{array}$ & $\begin{array}{l}\text { Climate and farming provides technical support and climate adaptation tools to networks of micro and small } \\
\text { farmers. It focuses on the introduction and production of Saffron (a non-native species) in Chile's central } \\
\text { valley, } 30 \text { to } 300 \text { kilometres from where James lives. }\end{array}$ \\
\hline Valentina & Industrial designer & Fashion in prison & $\begin{array}{l}\text { Fashion in prison is a social design brand of fashion accessories. Since the products are made by incarcerated } \\
\text { women, the social venture provides training and recreational workshops to them. Fashion in prison originated } \\
\text { from Valentina's degree project (and volunteering activities), focused on prison design. }\end{array}$ \\
\hline Santiago & $\begin{array}{l}\text { Forestry and } \\
\text { mining } \\
\text { development }\end{array}$ & Small farming & $\begin{array}{l}\text { Small farming supports small farmers in the O'Higgins region, } 730 \text { kilometres from where Santiago was } \\
\text { working at the time he launched his business. It provides guidance and training to low income food producers, } \\
\text { giving them also the opportunity to offer to market, sell and distribute their products via a dedicated online } \\
\text { platform. }\end{array}$ \\
\hline Rodrigo & Industrial engineer & Public spaces & $\begin{array}{l}\text { Public spaces designs and develops skate parks (public spaces 'for happiness') in vulnerable communities in } \\
\text { the Maule and Biobío regions, } 300 \text { to } 500 \text { kilometres from where the firm was originally founded. }\end{array}$ \\
\hline Arturo & Dental technician & Dental health & $\begin{array}{l}\text { Dental health offers health benefits to low income communities, in particular access to dental treatments and } \\
\text { counselling at a discounted rate. It operates in remote areas of the Biobío region, } 100 \text { to } 200 \text { kilometres where } \\
\text { the firm was originally founded. }\end{array}$ \\
\hline
\end{tabular}




\begin{tabular}{|c|c|c|c|}
\hline Carlos & $\begin{array}{l}\text { Construction } \\
\text { engineering }\end{array}$ & Organic food & $\begin{array}{l}\text { Organic food runs educational programmes around organic production and consumption to schools in low } \\
\text { income communities in the Andes part of the Araucania region. The firm was founded } 100 \text { kilometres from its } \\
\text { main operation, as part of an entrepreneurship course taken by Carlos in his first degree. }\end{array}$ \\
\hline Juan & $\begin{array}{l}\text { Business and } \\
\text { management }\end{array}$ & $\begin{array}{l}\text { Entrepreneurship } \\
\text { support }\end{array}$ & $\begin{array}{l}\text { Entrepreneurship support provides training and support to prospective entrepreneurs in poor communities, } 900 \\
\text { kilometres from where Juan lives. In that region it opens new sites of operation every year in neglected rural } \\
\text { and peripheral localities. }\end{array}$ \\
\hline Sebastian & $\begin{array}{l}\text { Engineer, } \\
\text { industrial } \\
\text { automation }\end{array}$ & Urban agriculture & $\begin{array}{l}\text { Urban agriculture is an organic farming social enterprise that focuses on organic agriculture and organic } \\
\text { composting in urban areas. It operates in peripheral areas of Santiago, though the business was originally } \\
\text { developed in Colombia. }\end{array}$ \\
\hline Roberto & Journalist & Social media & $\begin{array}{l}\text { Social media platform focused on building bridges and dialogue between people living in conflict areas, in } \\
\text { particular between Chileans and Mapuches (indigenous communities), } 900 \text { kilometres from where Roberto } \\
\text { lives and works. }\end{array}$ \\
\hline Ricardo & Architect & Community parks & $\begin{array}{l}\text { Community parks designs and builds community parks in poor communities by means of participatory } \\
\text { recovery of green areas and public spaces. Community parks operates nationwide, but none of the parks the } \\
\text { social enterprise have built are located in or near the areas where the founders and management team reside. }\end{array}$ \\
\hline Valeria & Market research & Ageing care & $\begin{array}{l}\text { Ageing care offers in-house non-medical support and care to the elderly. The social venture originated from a } \\
\text { focus group, conducted by Valeria, on products and services for people over } 60 \text {. It operates across Santiago, } \\
\text { but none of its clients live in or near the areas where the founder resides. }\end{array}$ \\
\hline
\end{tabular}


First order

$\mathrm{CP} 1$. Problem is institutionally derived

$\Leftarrow$ We realized why the spaces have not improved, it is because the municipalities do not have the capacity of management to be able to develop these projects. Because of the burden they have, the lack of time and the bureaucracy they have, the protocol they have to follow. The tenders are delayed by one or two years, three years, in order to be able to generate a project that is built, that is enabled, and that above all, is wrong. Poorly designed, poorly designed. Those were basically the two problems that we are covering, which we are solving. Public spaces

The original idea started with the elaboration and construction $\Rightarrow$ of housing with all the properties and sustainable technology to open it to the community and show it in an educational way. But that final project was a little distant, being young entrepreneurs with few resources. Then finally it was about adapting the project until we arrived at a change, instead of entering into construction. We began to think about what education and agrological production of food in each area is. Organic food

$\mathrm{CP} 2$. Problem is defined ex-ante

$\Leftarrow$ The first thing was to determine the market, even if it was a social company, obviously the market had to be defined to detect a financial and economic weakness. Then find the value proposition, that is, how do I know I have achieved a difference? And third, as I was able to project, not only at a level I had in mind, that it was Latin America that was basically the centre of Latin American business formation and development for the indigenous world. How did we manage to reach the indigenous community of Latin America? Indigenous entrepreneurship

I do not think it was in the best shape, but it was the way we $\Rightarrow$ could do it, within what we had. Maybe there could be better ones that require more capital, or require more impact, more territory or more hands, I do not know. What I do know is that we believed we had to do something and we would do it trying to innovate and if we have to change course again because there is a better way we will do it again. We will try to keep fulfilling our audience.

Social Media

CP3. Problem is clear

$\Leftarrow \underline{\text { I am seeing this problem clearly, as visualizing it as a business }}$ opportunity, which is that organic waste is not garbage, but is a gigantic opportunity to generate even energy. I think the biggest problems that exist in these communities here is that there is no community participation, it is terrible that and maybe it does not have much to do with my project but the greenhouses will generate that community participation too. Urban agriculture

Every day something new comes out from the needs of the $\Rightarrow$ people, from there come ideas. Listening to their stories one realizes what they need. Dental Health
First order

RP1. Problem is understood as evolving circumstances

RP2. Problem is defined ex-post

RP3. Problem is opaque 
CS1. Solution $\Leftarrow$ We are not yet in the stage of working with our beneficiaries ... space is given

\section{I am a plant molecular biologist and I could work any crop ... (so) we decided to work with small farmers in commune of Casa Blanca. Climate and farming}

There is work to do with the Aymara people, in the whole Easter $\Rightarrow$ Island, in Chiloé, Magallanes, there is a very diverse Chile in each territory, and not everyone sees that. The media does not help much in that sense, it is believed that we have only one type of Chilean, but this country is very diverse. Social Media

CS2. Boundaries and parameters are taken for granted

\section{$\Leftarrow$ We have had the opportunity to get feedback from some places} where we have gone to do things and people after a while tell us. I was well pleased. But there are some things that changed in the community and so, then that kind of comments from the people who have received from us some kind of workshop or benefit is very important, it is what we seek. Culture and arts

I believe that in three ways: first, as an observer, then to be on $\Rightarrow$ the street observing things, looking here and there. The other is brainstorming so I say I want to address this problem, then what I think of how to do it, then there begin to arise ideas and raise things. Like now that I'm doing a project for a shrimp community with respect to Chinchorro communities is patrimonial. I went to Arica, I got together with people and started to work; I put a blackboard and we started at a giant table with people throwing ideas and developing things Culture and arts

CS3. Solution is technical in nature
$\Leftarrow$ The technical problem is that small-scale agriculture cannot sell its products. Within the poverty spiral where they are, they have to pay for electricity, spend money on clothes, running expenses etc. But they have very little income. They cannot sell wheat because the contracts for the mills are about 30 hectares, then finally they cannot sell. It costs a lot, at most maybe some vegetables but the commercialization of these products is very difficult. So, the objective is to recover a source of income from their agricultural work. Small farming

All this information we based on matters that we had in our $\Rightarrow$ studies and much information also that gave us the community, older people, perhaps without professional studies. We are very close to senior citizens to see how the commune has changed, the changes it has had. Organic food
OS1. Solution space remains open

OS2. Boundaries are explored and rationalised

OS3. Experiential knowledge is utilised 
First order

AL1. Fitting in

process

$\Leftarrow \mathrm{I}$ think feedback with the team is key, but also mentoring and challenges are key because for me, the people of the Fablab helped me a lot to be able to have super strong feedback and change the radical idea. At first, I resisted but it made a lot of sense what they were telling me. So, the mentoring, the people that know these things, like incubators or accelerators and your team - I cannot do things without consulting these people first. Fabrication Lab

We began to relate to the people of Pucón, we began to do $\Rightarrow$ surveys, anthropological studies, to see what development alternatives were here in the commune. So, we decided to propose a logically healthy and viable development in the time that finally ended in these four areas of work. These are sustainable engineering, organic food, environmental education and culture and natural medicine. Organic food

AL2. Consulting: external legitimacy
$\Leftarrow$ Municipalities cannot do well because they do not have an inclusive or participatory methodology that can help them to develop their projects well. Here we engage with communities, learn from the disciplines and develop this. And to the extent that we do it for free, it is because that way we make sure that it works and we can streamline the whole process. Public spaces

The first contact was the board of neighbours, then we contacted $\Rightarrow$ the whole community in a frontal way, establishing the issue of trust, closeness and transparency; inviting them to participate in the whole process from children to adults. For us it is very important that the community participates, gets involved, then how we get there together is fundamental. Community parks
First order

CL1. Internal iteration and dialogue

CL2. Mutual learning processes

Reorienting social value

\begin{tabular}{|c|c|}
\hline First order & $\Leftarrow$ Representative data \\
\hline $\begin{array}{r}\text { PB1. Re- } \\
\text { considering } \\
\text { notion of justice }\end{array}$ & $\begin{array}{l}\Leftarrow \text { The most important idea was that the program had to be created } \\
\text { based on reality. Although we started with a standard programme } \\
\text { that could be replicated in certain communities and could be } \\
\text { developed, we finally concluded that the programme that was to be } \\
\text { carried out in each area needed to be done on the basis of a reality. } \\
\text { That is to say, you go to the territory, you see the productive } \\
\text { activity of the community and on that basis, you develop the profile } \\
\text { of the programme with those in the community. Indigenous } \\
\text { entrepreneurship }\end{array}$ \\
\hline $\begin{array}{r}\text { PB2. Re- } \\
\text { considering } \\
\text { relevant solutions }\end{array}$ & $\begin{array}{l}\Leftarrow \text { Before, what was done was that we generally designed a mesh, a } \\
\text { project but based on general interests. Today, no, today we go to } \\
\text { the territory and build from there what we intend to do ... I do not } \\
\text { know if we are really interested in working under a national policy, } \\
\text { and under a proposal that is not what we do, which is to work under } \\
\text { the reality produced from each locality. Indigenous } \\
\text { entrepreneurship }\end{array}$ \\
\hline $\begin{array}{r}\text { PB3. Re-oriented } \\
\text { actions }\end{array}$ & $\begin{array}{l}\Leftarrow \mathrm{I} \text { approached them, and got to know them, their experience, their } \\
\text { reality; (and) to make it feasible I had to bring the programme } \\
\text { down to earth, to this more concrete reality. Indigenous } \\
\text { entrepreneurship }\end{array}$ \\
\hline
\end{tabular}


Table 3. Abductive work

\begin{tabular}{|c|c|c|c|}
\hline First order code & Description and $\Rightarrow$ situational fit & Derived deductive contribution & Category \\
\hline $\begin{array}{l}\text { CP1. Problem is } \\
\text { institutionally } \\
\text { derived } \\
\mathrm{CP} 2 . \text { Problem is } \\
\text { defined ex-ante } \\
\mathrm{CP} 3 \text {. Problem is clear }\end{array}$ & $\begin{array}{l}\text { Sensemaking social problems by } \\
\text { specifying justice as a need to solve } \mathrm{n} \\
\text { institutionally defined issues. } \\
\quad \Rightarrow \text { Arrangement-focus }\end{array}$ & $\begin{array}{l}\text { Institutional imperfections: the gap between the existing and } \\
\text { the desired institutional arrangements (Roth and Kostova, } \\
\text { 2003) } \\
\text { Transcendental view: justice occurs through the desired } \\
\text { institutions (Sen, 2009) } \\
\text { Social entrepreneurs exploit institutional voids (Mair and } \\
\text { Marti, 2009) } \\
\text { Opportunities as failure of market institutions (Austin et al., } \\
\text { 2006) } \\
\text { Social problems historically framed by institutional actors } \\
\text { (Wadhwani, 2018) }\end{array}$ & $\begin{array}{l}\text { Conformist } \\
\text { problematizing }\end{array}$ \\
\hline $\begin{array}{l}\mathrm{CS} 1 \text {. Solution space } \\
\text { is given } \\
\mathrm{CS} 2 \text {. Boundaries and } \\
\text { parameters are taken } \\
\text { for granted } \\
\mathrm{CS} 3 \text {. Solution is } \\
\text { technical in nature }\end{array}$ & $\begin{array}{l}\text { Sensemaking solutions by defining } \\
\text { the solution space as closed } \\
\quad \Rightarrow \text { Arrangement-focus }\end{array}$ & $\begin{array}{l}\text { Path dependence: entrepreneurs continue along an } \\
\text { established path with their knowledge/information (Alvarez } \\
\text { and Barney, 2007) } \\
\text { Rhetorical closure and consensual stabilization (Pinch and } \\
\text { Bijker, 1984) }\end{array}$ & $\begin{array}{l}\text { Closed parameters of } \\
\text { solution space }\end{array}$ \\
\hline $\begin{array}{l}\text { AL1. Fitting in } \\
\text { process } \\
\text { AL2. Consulting: } \\
\text { external legitimacy }\end{array}$ & $\begin{array}{l}\text { Sensegiving solutions by } \\
\text { aligning/legitimizing with relevant } \\
\text { stakeholders } \\
\quad \Rightarrow \text { Arrangement-focus }\end{array}$ & $\begin{array}{l}\text { Legitimizing and complying with expectations of relevant } \\
\text { stakeholders (Suddaby et al., 2017) } \\
\text { Use of performance indicators to legitimise with } \\
\text { stakeholders (Beer and Micheli, 2017). } \\
\text { Attempting to influence the sensemaking of others (Gioia } \\
\text { and Chittipeddi, 1991). }\end{array}$ & Aligning \\
\hline
\end{tabular}

RP1. Problem is understood as evolving

circumstances
Sensemaking social problems by specifying justice as a need to solve constantly emergent issues.

$\Rightarrow$ Realization-focus
Problems considered by 'emerging' patterns of behaviour of individuals within institutional settings (Sen, 2009)

Entrepreneurs collectively act with beneficiaries and communities to define problems (Corner and Ho, 2010) Initially framed as local problems (Zahra et al., 2009)
Reflective problematizing 


\section{RP2. Problem is}

defined ex-post

RP3. Problem is

opaque

OS1. Solution space remains open

OS2. Boundaries are explored and

rationalised

OS3. Experiential

knowledge is utilised

CL1. Internal iteration and dialogue

CL2. Mutual learning processes
Sensemaking solutions by recognizing that they are always open

to change and evolution

$$
\Rightarrow \text { Realization-focus }
$$

Community oriented social entrepreneurship (Lumpkin

Bacq and Pidduck, 2018)

Justice requires observing actual behaviour of individuals within their institutional settings (Sen, 2009)

Problems and solutions are continuously effectuated

(Akemu et al., 2016)

Social bricoleurs (Zahra et al., 2009)

Social entrepreneurs co-creating solutions (Montgomery et al., 2012)

Sensegiving solutions by collaborating with relevant stakeholders

$\Rightarrow$ Realization-focus
Authenticity: an internalized ideal of the importance of collaboration (Suddaby et al., 2017)

Attempting to influence the sensemaking of others (Gioia and Chittipeddi, 1991).
Open parameters of solution space

\section{Collaborating}

PB1. Re-considering notion of justice

PB2. Re-considering relevant solutions

PB3. Re-oriented actions
Sensebreaking by facing critical juncture in idea and solution development

$$
\Rightarrow \text { Arrangement }>\text { Realization- }
$$

focus
Breakdown and destruction in meaning of prior path (Pratt

2000)

Breaking path dependency (Mahoney, 2000) 


\section{Table 4. Exhibits}

\# Participant

\section{Context}

1 Rodrigo, Public spaces

2 James, Climate and Farming

3 Arturo, Dental Health

4 Sebastián, Urban Closed parameters of agriculture solution space

Sebastián explains how they developed the composting technology

5 Juan, Open parameters of

Entrepreneurship solution space

support Juan describes how the programmes are run at community level

6 Gustavo, Culture Aligning and arts Gustavo highlights this process of alignment

\section{Qualitative evidence}

We realized why the spaces have not improved; it is because the municipalities do not have the capacity of management to be able to develop these projects. Because of the burden they have, the lack of time and the bureaucracy they have, the protocol they have to follow. The tenders are delayed by one or two years, three years, in order to be able to generate a project that is built, that is enabled, and that above all, is wrong. Poorly designed, poorly designed. Those were basically the two problems that we are covering, which we are solving.

The idea is to make this network of small farmers, who have the needs, but do not have the tools to adapt to climate change and allow them to generate added value and allow them to progress as a person, that's why we decided to work with small farmers.... We are not yet in the stage of working with them though (the farmers)...I have been heavily involved with the public sector I think it is key. Although they do not have that ambition [to solve the problem], they have in general their objective is the common good, because they are aligned with the approaches that we have, which helps us a lot.

I cannot bring a ball if they [users] need a kilo of rice. You have to have the knowledge but you will never know just by being sat in your vehicle outside a community you will never understand what is going on inside, within each family, you have to approach them, talk to them, understand them. Because it is not that they are not the same as us, but the opportunities that were given at the time did not know how to take advantage or did not give them opportunities.

The first thing was that we visualized the problem that is the discharge of waste organic matter. So, I needed information of the free trade shows that are reliable and hard data of this waste, where they go, who treats them, how they do it, etc. And then I needed information on business models, strategies, things like that in order to postulate; where to postulate, how we had to do it, how we could get this idea forward.

You are learning to work with the communities, they are all different, entrepreneurship support is a very very good programme, but not for all the communities you need an entrepreneurship support. When we choose a community we choose it a year in advance, it has to meet certain requirements. Because they are not arriving and settling, they have to be prepared or have to really need an entrepreneurship support to receive it, then, you have to understand how the community works, how it works with local leaders, how you can generate the bonds of trust, how a bond is generated.

The original idea was to start getting together with companies to generate artistic projects...then I started play with the social issue so I discovered that I could do projects that were of social impact with artistic or cultural tools. We took a new turn and now we are on the subject of creative culture, I think it is super necessary and can be a great contribution at a governmental and economic level to 
this country...I suddenly send the presentations and people tell me 'the work you do is incredible'. The Director of Peñalolén's Cultural Corporation told me I was awesome.

7 Sofia, Culture Aligning and ecology

Sofia explains how they deliver educational

programmes

8 Juan, Collaborating

Entrepreneurship Juan provides an example support of their collaborative process

9 Camila, Indigenous entrepreneurship

\section{Type-breaking}

Camila, the founder, explains how they shifted their thinking late in the process and reframed the problem and solution
We have had the opportunity to get feedback from some places where we have gone to do things and people after a while tell us that they were pleased, that there are some things that changed in the community and so. Then there are kind comments from the people who have received from us some kind of workshop or benefit. It is very important and something we seek.

Each community has its own specific things... our model is based on personal connections, one-toone collaborations, we focus on lifelong relationships, and there is no technology that can allow that. That's why I am telling you that it's very good for us because there are institutions that have been working for four years in a community that do not achieve the level of trust and relationships we manage to build in six months.

The most important idea was that the program had to be created based on reality. Although we started with a standard programme that could be replicated in certain communities and could be developed, we finally concluded that the programme that was to be carried out in each area needed to be done on the basis of a reality. That is to say, you go to the territory, you see the productive activity of the community and on that basis you develop the profile of the programme with those in the community. Before, what was done was that we generally designed a mesh, a project but based on general interests. Today, no, today we go to the territory and build from there what we intend to do ... I do not know if we are really interested in working under a national policy, and under a proposal that is not what we do, which is to work under the reality produced from each locality. 


\section{Figure 1 - Data Structure}

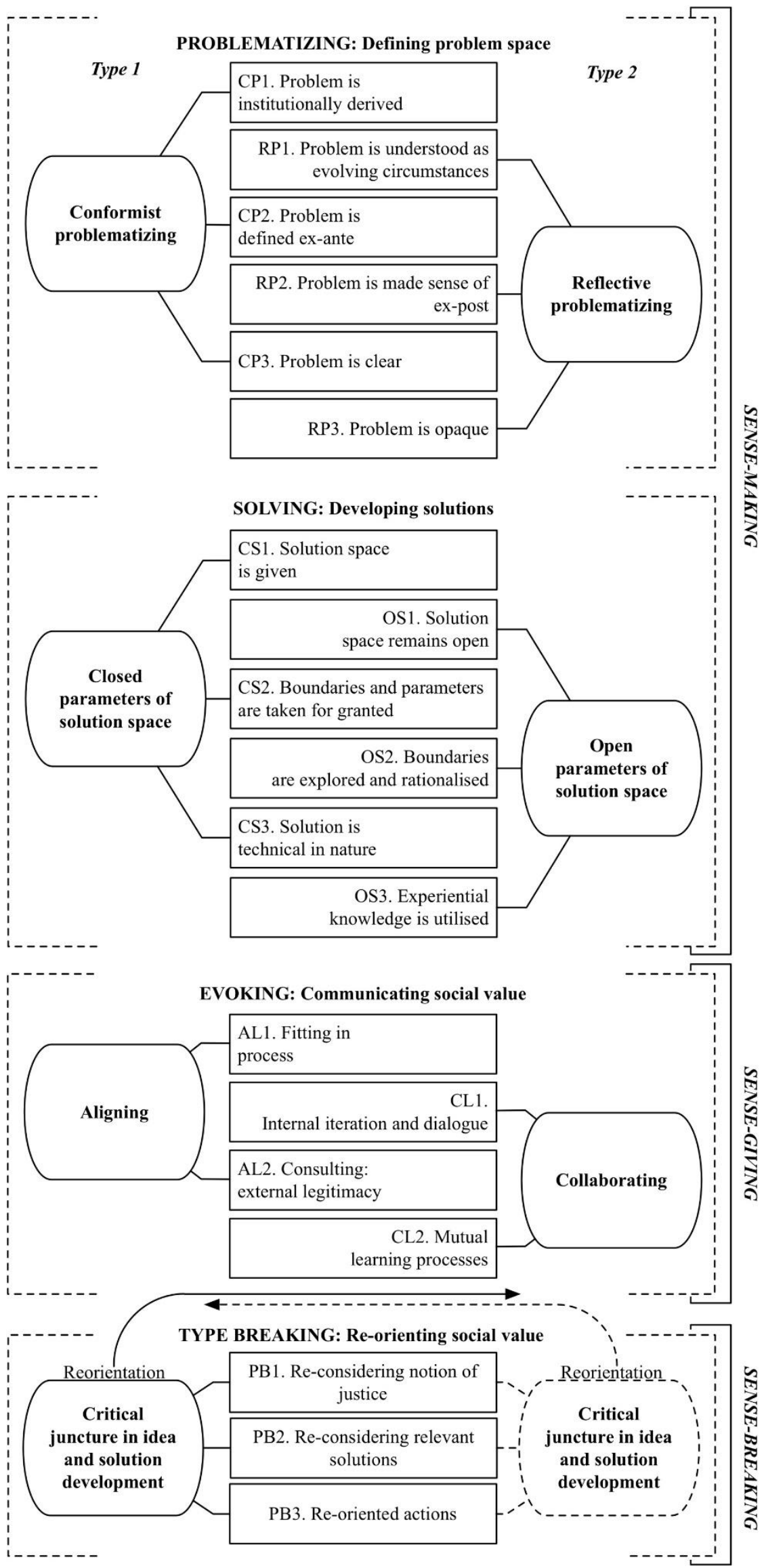


Figure 2. Theorised social sensemaking model

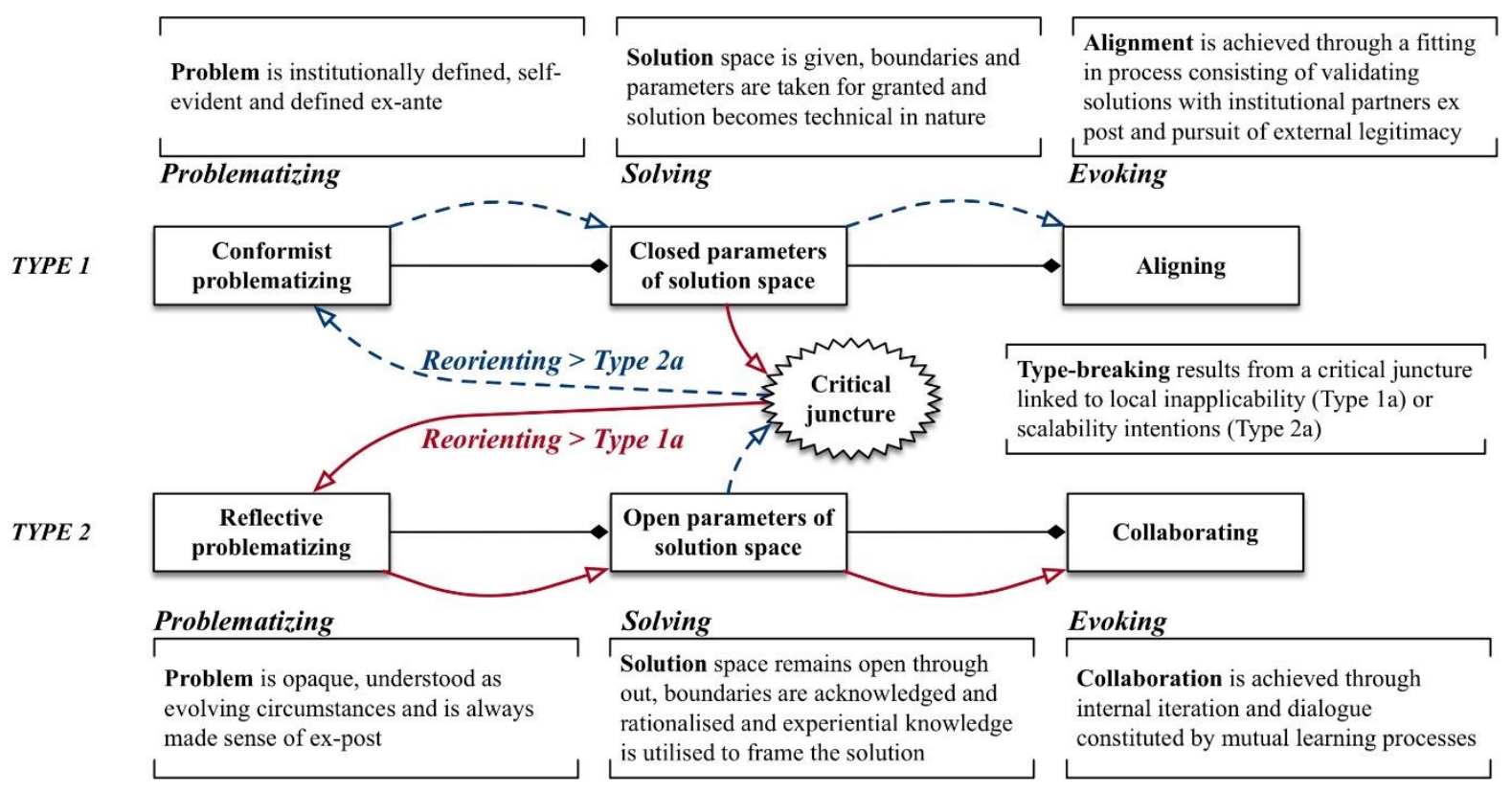

